\title{
Cascaded PID Controller Design for Heating Furnace Temperature Control
}

\author{
Y V Pavan Kumar, Arvapalli Rajesh, Sadhu Yugandhar, Viswaraju Srikanth \\ Engineering Test Services (ETS), Aerospace Business Unit, Honeywell Technology Solutions (Pvt) Ltd, India
}

\begin{abstract}
The paper evaluates the performance of cascaded PID controller designs for the temperature control of an industrial heating furnace. From the control theory literature it is clear that ideal PID controller is an obsolete for the control of non-linear processes like temperature. PID controller in cascaded architecture is the best choice compared to conventional single loop control system for controlling these nonlinear processes. However, it is constrained in choosing the better PID gains. Hence, this paper is such an approach to set the better values of PID gains in cascaded form by evaluating the performance with conventional tuning formulas. Performance analysis of various algorithms was carried out by finding the system's dynamic performance characteristics in each case. The entire system is modeled by using MATLAB/Simulink, The simulation results indicate that the proposed cascaded PID design could results to rapidity in response with robust dynamic performance.
\end{abstract}

Keywords - Cascaded Control System, Dynamic performance analysis, PID (Proportional plus Integral plus Derivative) controller, Temperature process control, Matlab/Simulink, Tuning concepts.

\section{INTRODUCTION}

One of the best flexibility with PID controllers is that by using two PIDs together, which achieves a better dynamic performance compared with single PID. This is known as cascaded PID controller. In this controller, the two PIDs are placed in such a way that the set point of one PID is controlled by another PID. One PID controller works as inner loop controller which takes the output of another PID as a set point. Another PID works as outer loop controller which controls the physical parameters of the system such as temperature, pressure, flow etc. Hence, cascaded PID controller reduces the time constant of the system and increases the controller working frequency.

Cascade control system has some distinguishing features. They are Quality control, Anti-interference, ability, flexibility and quickness. So it is generally used in following occasions

- Longer delay in control channel.

- Nonlinear controlled object and Large load change

- Acute change in the system

Mainly, cascade control system contains integrated sets of control loops. They are primary loop and secondary loops. The primary loop monitors the control variable and uses deviation from its set point to provide an output to the secondary loop. The secondary loop receives its set point from the primary loop and controls the reference variable accordingly.

In metallurgical industries, furnace is the most important thermal equipment used. Hence some basic methods have been recognized for automatic control of furnace temperature. For example, constant control of furnace process variables, cascade control of temperature in the furnace and flow of the fuel, the control of fuel and combustion air mixture ratio, and also control of oxygen content in flue gas. So far, the control focus has moved to performance optimization. The gas flow control primarily regulates the Furnace Temperature. Cascaded PID controller is well suited because the control of gas flow in the furnace is a typical process and larger capacity lag in the furnace temperature control system.

The dynamic quality of the entire system will be improved by pre-regulating the interference which influences the intermediate variables. The effectiveness of control of cascade control system is more efficient than single loop control system. And it has advantages over single loop in anti-jamming capability, rapidity, flexibility and quality control. The benefits of cascaded control system are effectively accounts for external disturbances, reduces dead time in variable response. Compatible with other control systems, such as feed-back and feed-forward control architectures. However it has some drawbacks since cascade control are multiple control loops, makes physical and computational architecture more complex and additional controllers and sensors can be costly.

\section{Furnance Cascade Control System}

The constituents of a furnace temperature control system are shown in figure.1. Whereas $\mathrm{T}_{1} \mathrm{C}$ is primary controller, $\mathrm{T}_{2} \mathrm{C}$ is secondary controller, $\mathrm{T}_{1} \mathrm{~T}$ represents measure temperature for the exports of raw 
materials, and $T_{2} T$ represents measure temperature of the furnace hearth. The basic operation of the furnace temperature control system is as follows.

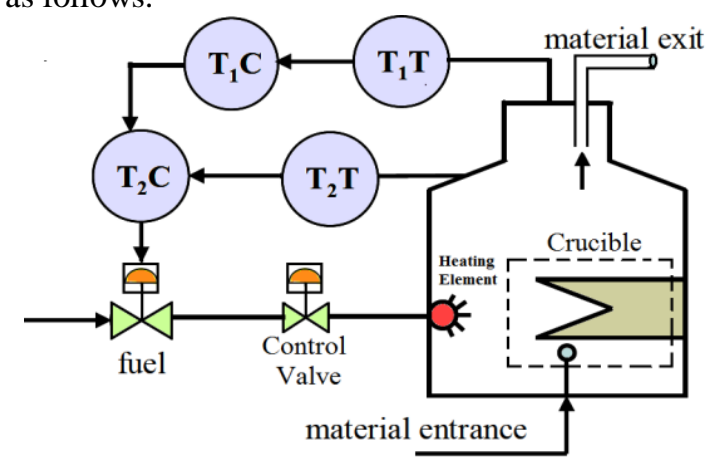

Figure.1 Cascaded control of furnace temperature system

The output of the primary controller $\left(T_{1} C\right)$ is given as set point to the secondary controller $\left(T_{2} C\right) . T_{2} C$ controls the fuel flow. In the heating process, material which is placed in the crucible is heated up to a specified temperature from the entrance to the exit. From fuel Combustion chamber to the raw material export, there are three capacity components in System temperature. They are furnace, hearth and the heated raw materials. Disturbances of load and in raw materials side are the system disturbances in one side and on the other side are the disturbances in the burning side, such as fuel, pressure, and air flow.

In the furnace temperature control system, the primary object is the raw material and the secondary object is the hearth in the furnace. The main controlled variable is the temperature of raw material in the export and sub controlled variable is the temperature of the hearth in the furnace. The primary disturbances are flow of the raw material and temperature of material at the inlet. The secondary disturbances are the pressure of the fuel before the valve, the heat value of fuel-air mixture supplied to furnace hearth etc.

One of the important precautions that must be taken in cascaded PID control system is that, in the selection of design parameters ensure that there is no matching problem of time constants of main and sub loops so that safe operation preventing resonance can be possible.

\section{Cascaded Pid Control System Design}

The figure. 2 shows the furnace cascade PID control system. The equations 1 and 2 are the transfer functions for Primary and secondary objects.

$$
\begin{aligned}
& G_{1}(s)=\frac{1 / 90}{(s+1 / 30)(s+1 / 3)} \\
& G_{2}(s)=\frac{1 / 10}{(s+1 / 10)(s+1)^{2}}
\end{aligned}
$$

This system is implemented in MATLAB/Simulink as shown in the figure.3 [1]. The equation.3 shows the mathematical representation of the PID controller and table.1 shows the effect of increaing $K_{P}, K_{I}$, and $K_{D}$ gains on dynamic characteristics.



Figure.2 Furnace cascade PID control system model

$$
P(t)=K_{p} e_{p}(t)+K_{I} \int_{0}^{t} e_{p}(t) d t+K_{D} \frac{d e(t)}{d t}
$$

Where; $\quad \mathrm{P}(\mathrm{t}) \quad=$ Control signal applied to the plant. 


\begin{tabular}{|c|c|c|c|c|}
\hline \multicolumn{5}{|c|}{$\begin{array}{l}K_{I}=\frac{K_{P}}{T_{I}}=\text { Integral gain constant } \\
K_{D}=K_{P} \times T_{D}=\text { Derivative gain constant. }\end{array}$} \\
\hline Parameter & Rise time (Tr) & Overshoot (Mp) & Settling time (Ts) & Error (Ess) \\
\hline $\mathrm{K}_{\mathrm{P}}$ & Decrease & Increase & Small change & Decrease \\
\hline $\mathrm{K}_{\mathrm{I}}$ & Decrease & Increase & Increase & Decrease Significantly \\
\hline $\mathrm{K}_{\mathrm{D}}$ & Minor Decrease & Decrease & Decrease & No effect \\
\hline
\end{tabular}

Table.1 Effect of increaing P, I, and D gains on dynamic characteristics

Hence, the PD controller is used to have fast settling; PI controller is used to have less steady state error. And PID controller is used to have all individual control actions. Hence, different combinations of controllers should be selected properly to get the desired characteristics. This paper uses ultimate gain/ultimate cycle methods for PID parameter tuning.

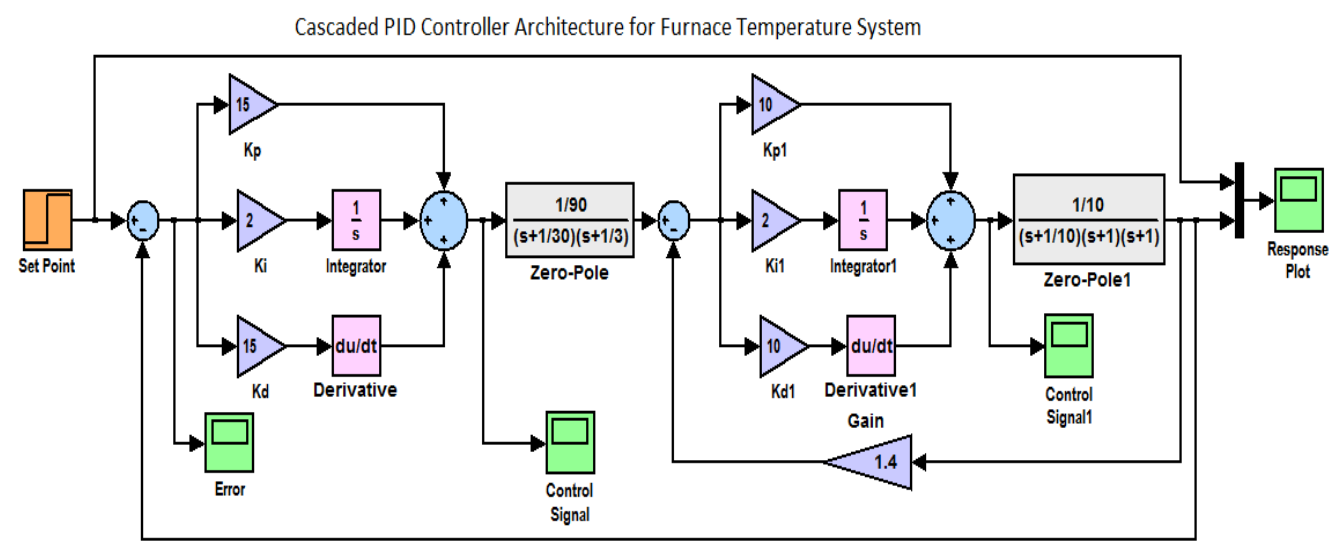

Figure.3 MATLAB/Simulink model of cascaded PID controller design for furnace temperature control

IV. ULTIMATE CYCLE METHOD FOR TUNING OF PID CONTROLLER GAINS

The ultimate cycle/ ultimate gain/ cyclic oscillations methods are the simple and more effective ways for setting up the PID controller gains. Basically, these methods are of three types, mentioned as follows [2].

- Ziegler-Nichols (ZN) PID controller tuning method.

- Modified Ziegler-Nichols PID controller tuning method.

- Tyreus-Luyben (TL) PID controller tuning method.

The furnace temperature in the industrial production has non-linear, time-varying and delay characteristics. Hence, we cannot create an absolute mathematical model. It is always a painful and challenging task to select proper values for $\mathrm{K}_{\mathrm{P}}, \mathrm{K}_{\mathrm{I}}$, and $\mathrm{K}_{\mathrm{D}}$ gains. To reduce the above problems and to improve transient response specifications, the outer loop PID is tuned by using tuning algorithms. Tuning of PID controller involves the best selection of values for proportional $\left(\mathrm{K}_{\mathrm{P}}\right)$, integral $\left(\mathrm{K}_{\mathrm{I}}\right)$ and derivative $\left(\mathrm{K}_{\mathrm{D}}\right)$ gains.

The following are the steps to calculate critical gain $\left(\mathrm{K}_{\mathrm{C}}\right)$ and critical time period $\left(\mathrm{T}_{\mathrm{C}}\right)$ values [3], [4], [5], and [6]. Figure.4 shows the process flow of PID controller gain settings [7].

Step-1: Reduce integral and derivative actions to their minimum effect i.e. design the system with proportional controller only and with unity feedback.

Step-2: Gradually begin to increase the proportional gain value until the system exhibits the sustained oscillations.

Step-3: This gain at which the system exhibits steady cycling or sustained oscillations about the set point is called critical gain $(\mathrm{Kc})$. The time period corresponding to these oscillations is called as critical time period (Tc).

Step-4: Note the values of these Kc and Tc.

Step-5: From these values, calculate $\mathrm{Kp}, \mathrm{Ki}$, and $\mathrm{Kd}$ gain values based on the method considered as shown in the Table.2. 


\begin{tabular}{|c|c|c|c|}
\hline \hline Parameter & $\begin{array}{c}\text { Ziegler- Nichols PID controller } \\
\text { Tuming Formula }\end{array}$ & $\begin{array}{c}\text { Modified Ziegler- Nichols PID } \\
\text { controller Tuming Formula }\end{array}$ & $\begin{array}{c}\text { Tyreus-Luybenl PID controller } \\
\text { Tuming Formula }\end{array}$ \\
\hline $\mathrm{T}_{\mathrm{I}}$ & $T_{I}=\frac{T_{C}}{2}$ & $T_{I}=T_{C}$ & $T_{I}=2.2 \times T_{C}$ \\
\hline $\mathrm{T}_{\mathrm{D}}$ & $T_{D}=\frac{T_{C}}{8}$ & $T_{D}=\frac{T_{C}}{3}$ & $T_{D}=\frac{T_{C}}{6.3}$ \\
\hline $\mathrm{K}_{\mathrm{P}}$ & $\mathrm{K}_{\mathrm{P}}=0.6 \times \mathrm{K}_{\mathrm{C}}$ & $\mathrm{K}_{\mathrm{P}}=0.2 \times \mathrm{K}_{\mathrm{C}}$ & $\mathrm{K}_{\mathrm{P}}=0.45 \times \mathrm{K}_{\mathrm{C}}$ \\
\hline $\mathrm{K}_{\mathrm{I}}$ & $K_{I}=\frac{K_{P}}{T_{I}}$ & $K_{I}=\frac{K_{P}}{T_{I}}$ & $K_{I}=\frac{K_{P}}{T_{I}}$ \\
\hline $\mathrm{K}_{\mathrm{D}}$ & $K_{D}=K_{P} \times T_{D}$ & $K_{D}=K_{P} \times T_{D}$ & $K_{D}=K_{P} \times T_{D}$ \\
\hline
\end{tabular}

Table. 2 Tuning formulas for PID controller design in different methods

Figure. 5 shows, the overall MATLAB/Simulink model for PID controller design with different tuning methods. The parameter gain values obtained for different PID controllers are listed in Table.3. Figure. 6 shows the elaborated design of the furnace system with Ziegler-Nichols PID controller.

\begin{tabular}{|c|l|c|c|c|c|c|}
\hline S.NO & METHOD NAME & Kp & Ti & KI & TD & KD \\
\hline 1 & $\begin{array}{l}\text { Ziegler- } \\
\text { Nichols(ZN) tuning } \\
\text { formula }\end{array}$ & 24.24 & 5.238 & 4.627 & 1.3095 & 31.742 \\
\hline 2 & $\begin{array}{l}\text { Tyreus-Luyben } \\
\text { tuning formula }\end{array}$ & 18.18 & 23.047 & 0.788 & 1.662 & 30.215 \\
\hline 3 & $\begin{array}{l}\text { ModifiedZiegler- } \\
\text { NicholsTuning } \\
\text { formula }\end{array}$ & 8.08 & 10.476 & 0.771 & 3.492 & 28.215 \\
\hline \hline
\end{tabular}

Table.3 P, I, D parameters obtained for different tuning formulas

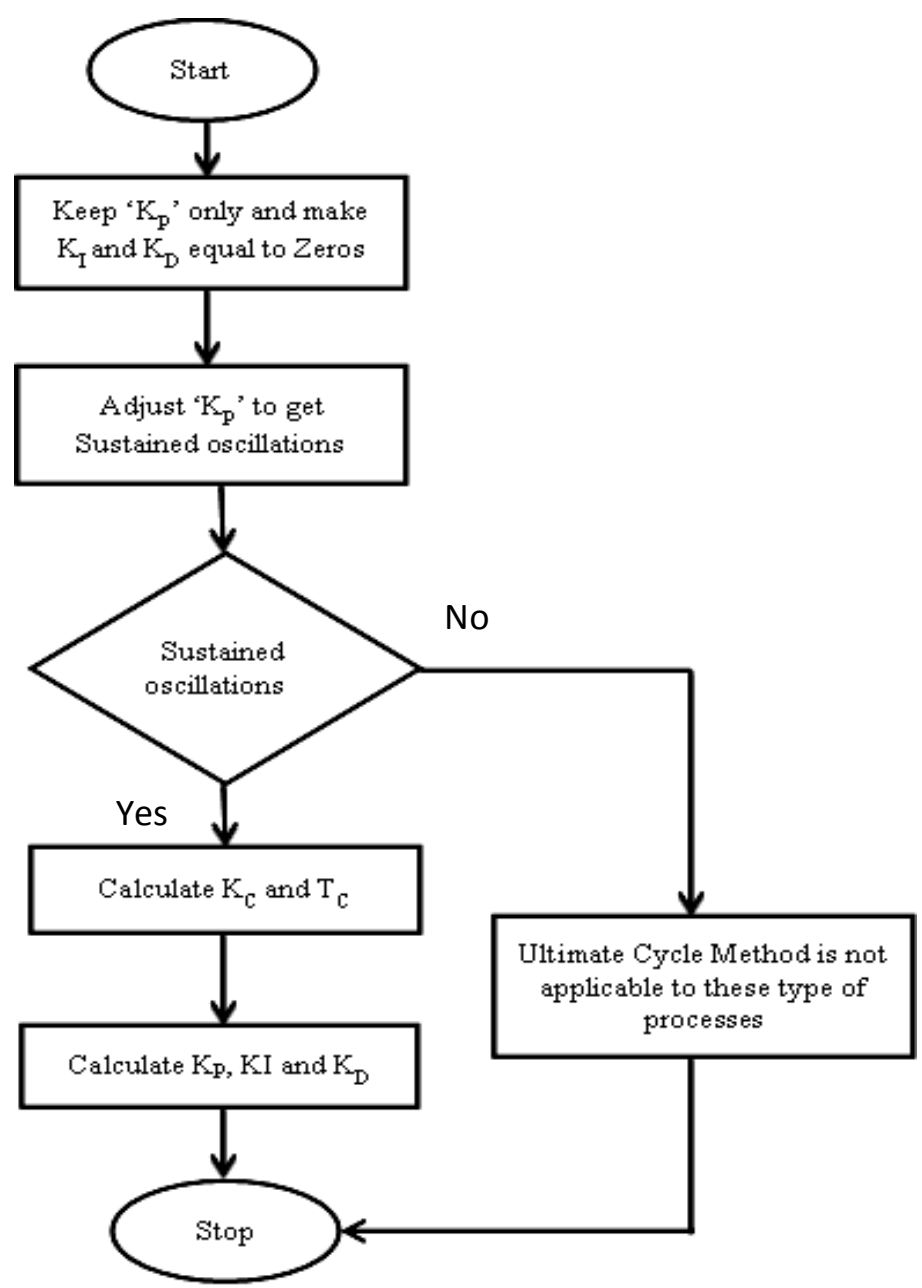

Figure.4 Flow chart for PID tuning procedure 




Figure.5 Comparison model for all the methods.

\section{Dynamic Performance Characteristics}

The change of response of a closed loop system with respect to time is called as dynamic response [8]. This time response can be analyzed by calculating the following parameters.

- Rise time $\left(\mathbf{T}_{\mathbf{r}}\right)$ : The Rise time refers to the time required for the response of the system to reach from a low value to a high value. Typically, these values are $10 \%$ and $90 \%$ of the steady-state value respectively.

- Delay-Time $\left(\mathbf{T}_{\mathrm{d}}\right)$ : The delay time refers to the time required for the response of the system to reach from zero to $50 \%$ of the steady-state value for the first time.

- Settling Time $\left(\mathbf{T}_{\mathbf{S}}\right)$ : The settling time refers to the time taken for the response to reach and remains in a specified error band. The tolerable error band is usually (2-5) \% of the steady-state value.

- Steady-state Error $\left(\mathbf{E}_{\mathbf{S S}}\right)$ : The steady-state error is the difference between the actual response and desired response when the system reaches the steady state.

- Peak overshoot $\left(\mathbf{M}_{\mathbf{P}}\right)$ : The peak overshoot refers to the ratio of first peak value measured from steady-state value to the steady-state value.

- Peak Time: The peak time refers to the time taken by the response to reach the first peak overshoot.

- Stability: A system is said to be stable if the system produces bounded output for a bounded input.

The ideal response of the system will have quick rising, minimum delay time, zero steady-state error, quick settling, minimum overshoot, and stability.

\section{Simulation Results}

Figure.7 shows the formation of sustained oscillations about the set point. Figures 8-11 shows the response of the system with PID controller designed with various tuning formulas. Figure 12 shows the comparative result for all the responses. The transient response/dynamic performance characteristics are calculated and tabulated as shown in the table.4.

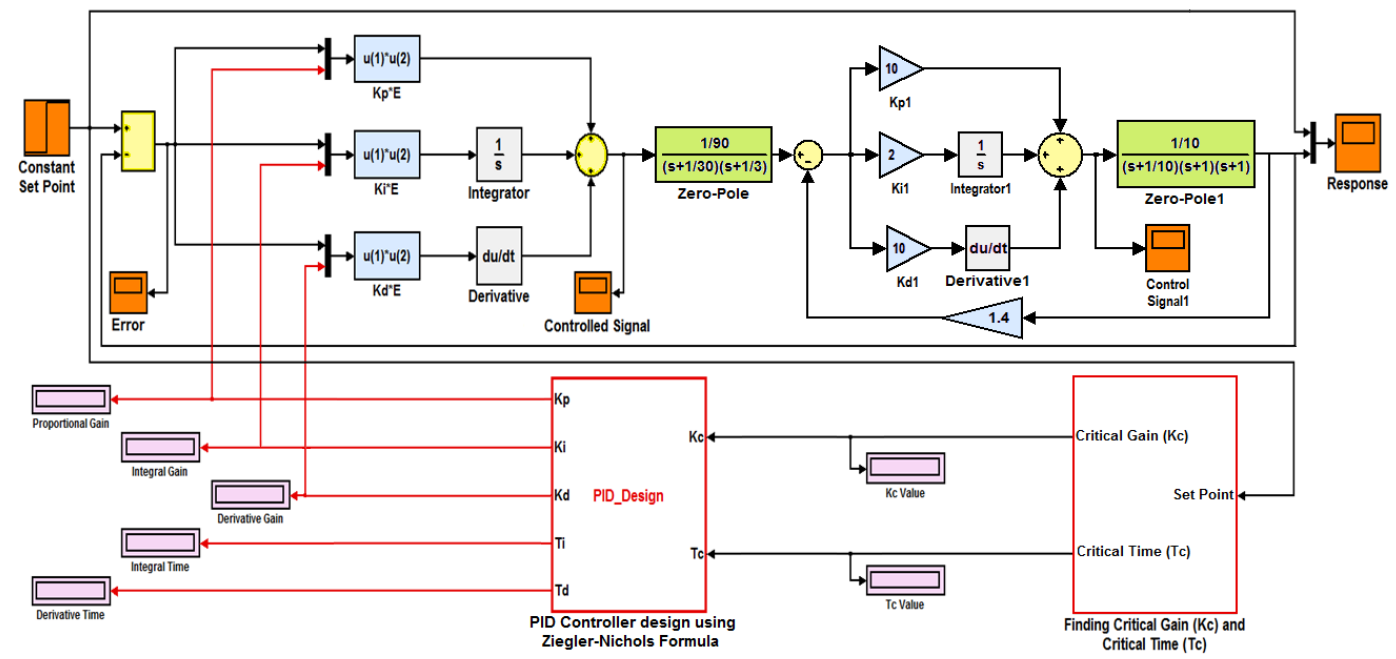

Figure.6 MATLAB/Simulink model of the furnace system with Ziegler-Nichols cascaded PID controller 

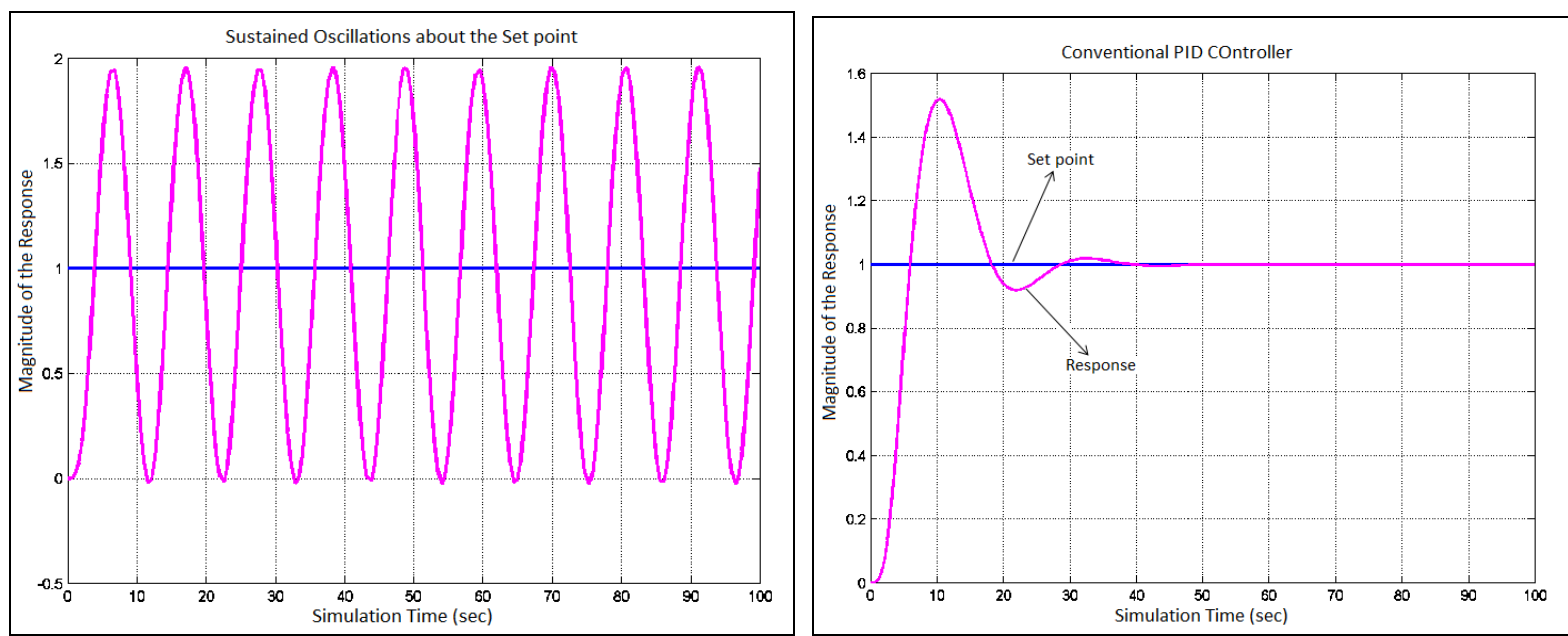

Figure.7 Sustained oscillations about set point



Figure.9 System response with cascaded ZN PID

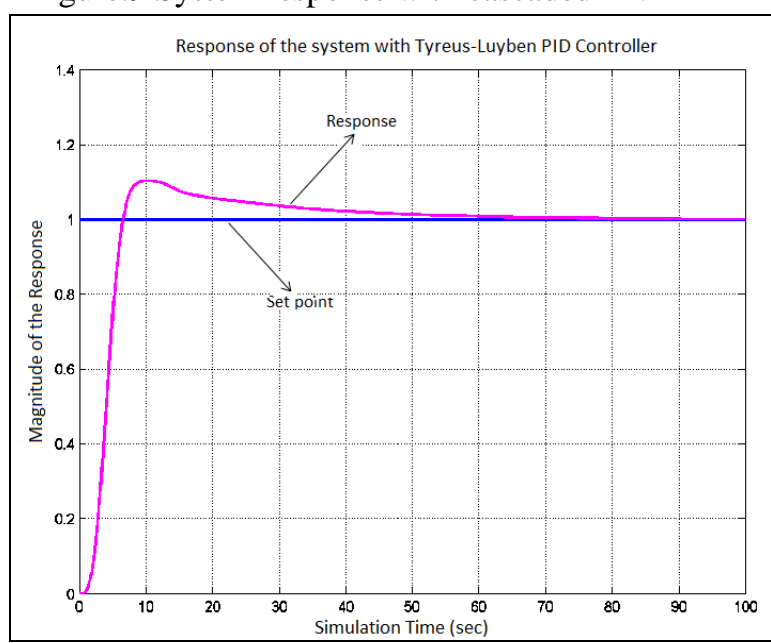

Figure.11 System response with cascaded TL PID

Figure.8 System response with generic PID controller

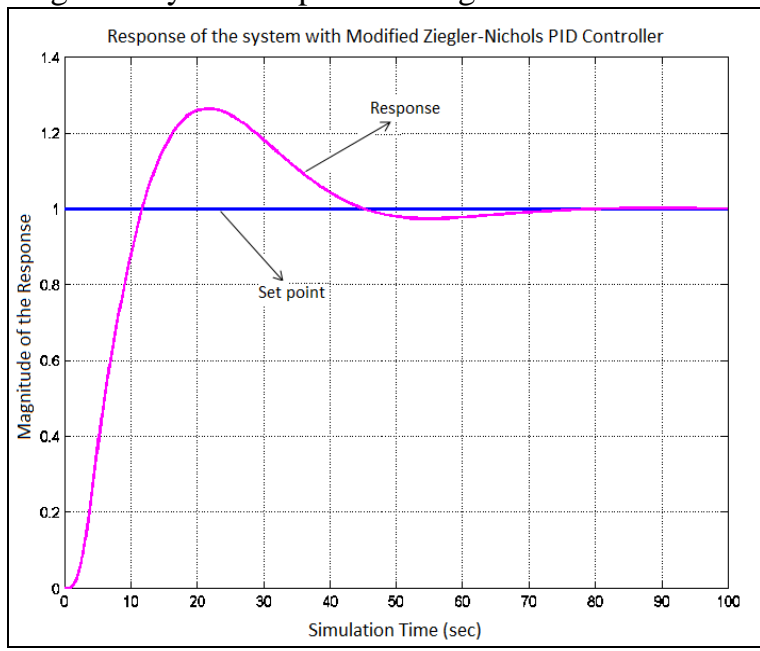

Figure.10 Response with cascaded Modified ZN PID



Figure.12 Comparison of all responses 
Cascaded PID Controller Design for Heating Furnace Temperature Control

\begin{tabular}{|c|c|c|c|c|c|c|c|}
\hline \multirow{2}{*}{ S. No. } & \multirow{2}{*}{$\begin{array}{c}\text { Controller } \\
\text { Used }\end{array}$} & $\begin{array}{c}\text { Time Domain Performance Parameters } \\
\text { Delay Time } \\
\left(\boldsymbol{T}_{d}\right) \text { in Sec }\end{array}$ & $\begin{array}{c}\text { Rise Time } \\
\left(\boldsymbol{T}_{r}\right) \text { in Sec }\end{array}$ & $\begin{array}{c}\text { Settling Time } \\
\left(\boldsymbol{T}_{s}\right) \text { in Sec }\end{array}$ & $\begin{array}{c}\text { Peak } \\
\text { Overshoot } \\
\left(\boldsymbol{M}_{\boldsymbol{P}}\right) \text { in \% }\end{array}$ & $\begin{array}{c}\text { Transient } \\
\text { Behavior }\end{array}$ & $\begin{array}{c}\text { \% Steady } \\
\text { state Error } \\
\left(\boldsymbol{E}_{S S}\right)\end{array}$ \\
\hline 1. & $\begin{array}{c}\text { Ziegler- } \\
\text { Nichols PID } \\
\text { Controller }\end{array}$ & 2.763 & 2.456 & 38.40 & $58.20 \%$ & Oscillatory & 0 \\
\hline \multirow{2}{*}{2.} & $\begin{array}{c}\text { Modified } \\
\text { Ziegler- } \\
\text { Nichols PID } \\
\text { Controller }\end{array}$ & 5.296 & 7.644 & 78.285 & $31.52 \%$ & Oscillatory & 0 \\
\hline 3. & $\begin{array}{c}\text { Tyreus- } \\
\text { Luyben PID } \\
\text { Controller }\end{array}$ & 3.377 & 3.531 & 67.175 & $11.02 \%$ & Smooth & 0 \\
\hline
\end{tabular}

Table.4 Comparison of different time domain specifications

\section{Conclusion}

In the paper firstly, the conventional PID controller is used as temperature process controller for Industrial heating furnace. Later on various tuning algorithms are used to tune the cascaded PID controller gain parameters. The performance of all is evaluated against each other and tabulated as Table. 4. From the table, the following points can be observed.

$\checkmark$ Even though, the Ziegler-Nichols PID controller produces the response with lower delay time, rise time and settling time, it has severe oscillations with a very high peak overshoot of $58.20 \%$. This causes the damage in the system performance.

$\checkmark \quad$ In the case of Tyreus-Luyben PID Controller, the values of delay time, rise time, and settling time are better in comparison with Modified Ziegler-Nichols method, and almost identical to the Ziegler-Nichols method. Also, it offers major advantage in terms of smooth transient behaviour and less overshoot.

Hence, it is concluded that the Tyreus-Luyben tuning algorithm is best suited for setting up the values of cascaded PID controller gains, to be used for controlling non-linear processes such as temperature.

\section{REFERENCES}

[1]. Liu Jinkun, “MATLAB Simulation of Advanced PID Control [M],” Electronic Industry Press, Beijing, 2006, pp. 102-129.

[2]. Ge Lusheng Tao Yonghua, and Yin Yixin, "New Type of PID Control and Its Application [M]," 2000, pp.101-142.

[3]. Zhuzhen wang, Xiaodong Zhao, and Haiyan Wang, Design of series leading correction PID controller," In the proc. of IEEE International Conference, 2009

[4]. Guo Lin Jin Jing, the new PID parameters selection in the furnace control applications, industrial instrumentation and automation equipment, 2010(1): 92-93

[5]. Tang Xianlun, Li Yinguo, Chou Guoqing, and Cao Xiu, the PID algorithm in cascade control system based on MATLAB, Chongqing University,2005 (9): 61-63

[6]. Wang Zhenglin, Guo Yangkuan,. Process control engineering and simulation. Beijing: Electronic Industry Press, 2009.

[7]. Duan Baoyan, Su Yuxin, A new nonlinear PID controller. Control and Decision, 2003, 18 (1):126-128.

[8]. Curtis D Johnson, "Process Control Instrumentation Technology," Pearson Education, 2009.

[9]. Nagoor kani. A, "Control Systems," First edition, RBA Publications, 2002.

\section{AUTHOR BIOGRAPHIES}

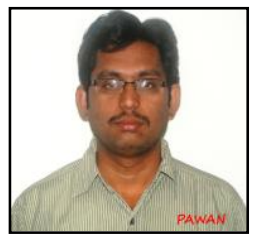

Y V Pavan Kumar received B. Tech in the area of Electrical and Electronics Engineering in 2007 from JNTU Hyderabad, India, M.Tech in the area of Instrumentation and Control Systems in the year 2011 from JNTU Kakinada, India. He has 2 years of teaching experience in Electrical Engineering, and 2 years in Control, Power Systems, and Engineering Test Systems Design for Aerospace Systems. Currently he is working as a Design Engineer in Aerospace Engineering Test Services, Honeywell Technology Solutions Lab, India. He has published 25 research papers in International Journals/Conferences and 2 International monographs. His research area includes Power systems, Aerospace Systems, Advanced Control systems, and Artificial Intelligence.



Arvapalli Rajesh received B. Tech in the area of Electrical and Electronics Engineering in 2009 from JNTU Hyderabad, India, M.Tech in the area of Power Electronics Systems in the year 2012 from Osmania University, India. Currently he is working as a Design Engineer in Aerospace Engineering Test Services, Honeywell Technology Solutions Lab, India. His research area includes Power Electronics, Power systems, Aerospace Systems. 

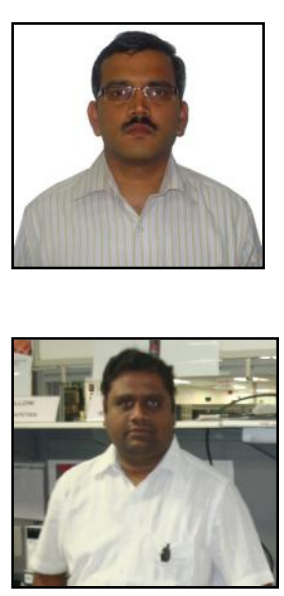

Yugandharababu Sadhu received Bachelor of Engineering in the area of Electronics and Communication Engineering. He has an overall experience of 15+ years, in which 7+ years worked with Bharat Electronics Ltd Bangalore and 8+ years in Engineering Test Systems Design for Aerospace Systems. Currently he is working as a Technology Specialist in Aerospace Engineering Test Services, Honeywell Technology Solutions Lab, India. He has published 1 IEEE paper on flight control systems design. His research areas include Electronic Controllers and Aerospace Systems.

Srikanth Viswaraju received Bachelor of Engineering in the area of Electronics and Communication Engineering from Bangalore University, Bangalore India. He has an overall experience of 10+ years, in which 3+ years worked with Tata Elxsi Ltd Bangalore in the area of Embedded Systems group and 6+ years in Engineering Test Systems Design for Aerospace Systems. Currently he is working as a Project Lead in Aerospace Engineering Test Services, Honeywell Technology Solutions Lab, India. His research areas include Embedded Systems and Aerospace Systems. 